\title{
Vocational Rehabilitation after Acquired Brain Injury: A Swedish Study of Benefits and Costs
}

\author{
Kersti Samuelsson*, Maria Tropp, Anna Lundqvist \\ Clinical Department of Rehabilitation Medicine and Department of Medicine and Health Sciences, Linköping \\ University, Linköping, Sweden \\ Email: ${ }^{*}$ Kersti.Samuelsson@lio.se
}

Received 27 June 2014; revised 28 July 2014; accepted 11 August 2014

Copyright (C) 2014 by authors and Scientific Research Publishing Inc.

This work is licensed under the Creative Commons Attribution International License (CC BY). http://creativecommons.org/licenses/by/4.0/

(c) (i) Open Access

\begin{abstract}
Purpose: To examine the benefits from a vocational rehabilitation program for patients suffering from Acquired Brain Injury (ABI) in terms of quality of life, and overall health. In addition, to examine the direct societal costs of healthcare interventions related to vocational rehabilitation and indirect societal costs related to production loss. Method: Identified interventions in 45 patients with ABI who were discharged from a vocational rehabilitation program between 2010 and 2011 were documented, classified and translated into costs. Expenses associated with production loss were calculated by comparing sick leave production loss at first contact with the team, with sick leave production loss at discharge. Health related QoL and overall health, was measured at first contact and at discharge by using the EQ5D. Results: For vocational rehabilitation interventions, mean costs were $€ 6303$ /individual/month. At first contact with the team, mean production loss was estimated to be $€ 4409$ /individual/month compared; at discharge to be $€ 2446$. QoL-ratings increased from first contact to discharge, although estimated health did not change. At discharge, significant correlations were found between QoL ratings and estimated health and the extent of production loss $(p<0.05)$. Conclusion: Healthcare interventions that help ABI patients resume work are cost effective for society as well as for patients.
\end{abstract}

\section{Keywords}

Clinical Evidence, Health Economics, Return to Work, Work Training

\footnotetext{
${ }^{*}$ Corresponding author.
}

How to cite this paper: Samuelsson, K., Tropp, M. and Lundqvist, A. (2014) Vocational Rehabilitation after Acquired Brain Injury: A Swedish Study of Benefits and Costs. Open Journal of Therapy and Rehabilitation, 2, 133-145. 


\section{Introduction}

\subsection{Acquired Brain Injury (ABI)}

ABI consists of different non-congenital traumatic or non-traumatic diseases and injuries affecting the brain [1]. The World Health Organization defines ABI as "Damage to the brain which occurs after birth and is not related to a congenital or degenerative disease. These impairments may be temporary or permanent and cause partial or functional disability or psychosocial maladjustment" [2]. Most common ABI are stroke and traumatic brain injury. However, among diagnoses that can cause $\mathrm{ABI}$ are also tumour, infection, hypoxia, substance abuse and neuropsychiatric diseases [1]. Thus, ABI might result from a number of different causes.

$\mathrm{ABI}$ is one of the most long-term cognitive impairments and disability in the western countries [3]-[5] affecting neurological, psychiatric and cognitive functions which make return to work difficult. It represents a major health burden in western countries with an annual incidence of 100 - 300 per 100,000 inhabitants [6]. About 70,000 persons suffer from ABI in Sweden every year [7]. Although not all ABI patients have visible dysfunctions, that is they can walk and talk, $2 / 3$ of these patients have been shown to suffer from attention problems, slow information processing, and enhanced sensitivity to stress and overloading, manifestations that can cause mental fatigue and stress and might limit the ability to return to work [8] [9]. ABI patients self-identify several common symptoms: distractibility, fatigue when concentrating, and difficulties performing two tasks simultaneously [10].

\subsection{Vocational Rehabilitation}

Vocational rehabilitation for ABI consists of interventions aimed at preparing the patient for the activities and demands necessary to live an optimal life. For those between 18 - 65 years of age, it ideally includes a return to work. When vocational rehabilitation is successful, patients return to the labor force and participate in social contexts on equal terms as others. For every patient who manages to return to work, society will save money, an advantage that makes vocational rehabilitation a winning concept. However, healthcare providers must remember that preparing someone who has acquired brain injury for a return to the labor force is challenging. Residual symptoms such as attention problems, slow information processing, and enhanced sensitivity to stress and overloading, which in turn causes mental fatigue and stress, affect one's ability to manage different demands in society and especially at work. There is most often a need for some kind of Therapeutic Return to Work (TRW) including a close contact with the workplace management, and a gradual exposure to appropriate tasks [11]. Several studies have demonstrated the importance of on-going professional support and the need for professional assistance in adapting the workplace and/or tasks for each individual's specific abilities and needs [12] [13]. For example, Nishino et al. [14] showed that of the $71.5 \%$ patients in their study with subarachnoid hemorrhage and who returned to work, only $58.5 \%$ returned to the same job or workplace.

Vocational rehabilitation programs for patients suffering from mild or moderate cognitive dysfunction after $\mathrm{ABI}$ traditionally focus on the consequences of cognitive deficits on everyday life and possibilities of returning to work. Those cognitive deficits often require a change of occupation and/or job demands [15]. Within the vocational rehabilitation field, there are different models, which have shown positive results according to the outcome in return to work [10] [13].

There is evidence of a strong and consistent positive correlation between social integration, perceived quality of life, and employment [15] [16]. In addition it is of significant importance for society to reduce costs caused by sick leave due to long-term disease and injury. Therefore, medical rehabilitation plays an important role both from an individual as well as from a socioeconomic point of view.

\subsection{Predictors for Work Resumption after ABI}

Different definitions of work resumption, national differences of labour market legislation, and cultural differences make it difficult to interpret and compare reported results from different countries. However, about $50 \%$ $70 \%$ of ABI patients who have participated in structured multi-disciplinary vocational rehabilitation programs return to work [10] [16] [17]. In a literature review, Van Velzen et al. [15] report that irrespective of intervention about $40 \%$ of non-traumatic as well as traumatic ABI patients returned to work after two years. This review found no effect associated with cause or time since injury. Clearly, several factors influence a person's possibility to return to work. In a regression analysis, Johnstone et al. [18] showed that the most powerful predictor for 
returning to work after TBI is access to vocational rehabilitation.

\subsection{Costs and Benefits}

In the 2005 Cochrane review, the authors highlight the need for more individualized interventions as well as evaluation methods related to the varied nature of ABI, suggesting future research should be based on the fact that many questions remain to be answered regarding the effectiveness of rehabilitation interventions and that the methods might have to be alternative methodologies to Randomized Controlled Trials (RCTs) [19]. For example, there is a need to further explore cost-effectiveness and impact on quality of life for patients [10] [19].

There has been an increasing strain on the social welfare systems in the Western countries during the last decades and it is very costly for a country if a considerable part of the work force is on sick leave. In the UK, for example, the economic cost of incapacity has been estimated to exceed 115 billion Euros a year [20]. The cost for people on sick leave can be direct or indirect [21]. Direct costs are associated with medical and paramedical treatments and medication, and indirect costs are associated with production loss and decreased tax revenue. Thus, the economic benefit of medical and vocational rehabilitation programs can be estimated in increased production due to decreased sick leave. We assume that vocational rehabilitation is cost-effective and that society can save resources by offering effective professional rehabilitation to patients suffering from ABI as a preferred alternative to sick leave and disability pension. An economic evaluation has to deal with inputs as well as outputs, often called costs and consequences; economic evaluation is defined as "the comparative analysis of alternative courses of action in terms of both their costs and consequences" [22].

\subsection{Swedish Social Insurance [23]}

Social insurance is an important part of the Swedish social security system. It covers everyone who lives or works in Sweden and provides financial protection for persons with disability, injury, or illness. A person can receive sick benefits for about one year. The benefit is based on his/her annual income. If the individual's working capacity is permanently reduced and all possibilities to resume work have been tried, the person can receive sickness compensation [disability pension], which can be full, three-quarters, half, or one-quarter, depending on how much the work capacity has been reduced. The individual has an opportunity to practice up to one year at his/her ordinary job to test and increase working capacity.

\subsection{Multi-Disciplinary Vocational Rehabilitation}

At the Department of Rehabilitation Medicine at the University Hospital of Linköping, Sweden, we have structured a multi-disciplinary vocational rehabilitation program for patients with ABI as part of the outpatient rehabilitation services. This special program supports patients in the process of returning to work. The specialized multi-disciplinary rehabilitation team consists of a MD, physiotherapist, neuropsychologists, and occupational therapists (OT). When needed, a speech therapist and a social worker can serve on the team. The vocational rehabilitation program contains three stages (Figure 1). It starts with medical and brain injury assessments that includes a comprehensive brain injury assessment of the individual's condition using a medical examination, neuropsychological assessment, sensory-motor assessment, activity assessment (including evaluation of brain injury consequences on daily living and work, education, and work anamnesis), and attitudes assessment concerning a return to work. During the second stage, the individuals participate in neuropsychological and physical rehabilitation programs at the clinic including individual and/or group activities aimed at improving certain functions and strengthening emotional, social, and behavioral capacity (Figure 1). The programs focus on pre-work training: increasing self-awareness, understanding the consequences of the injury, and developing coping strategies that prepare the individual for work training [24]. In the last stage of the vocational rehabilitation, the team plans, executes, and follows-up on a work training program designed for each patient's specific needs. Most often this is done at the person's ordinary workplace in collaboration with the patient, employer, and the social insurance official.

It is of utmost clinical importance to plan a rehabilitation program using evidenced-based principles and a patient-centered perspective. Thus, a combination of interventions should be available for each patient, individually adjusted for each individual's abilities and needs [25]. However, the societal savings as well as costs from offering these individually adjusted programs are seldom scrutinized. Consequently, this study's primary objective 


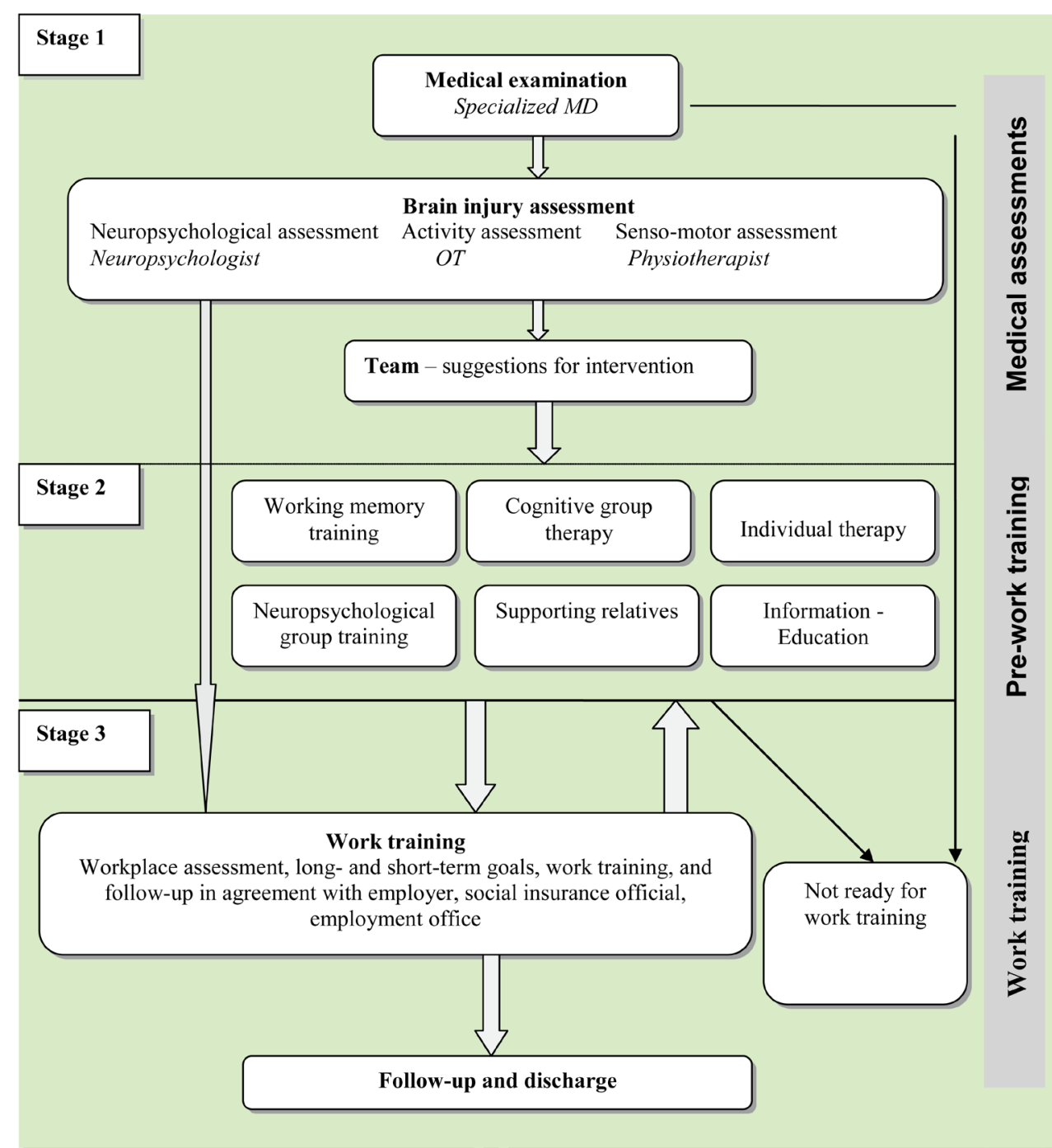

Figure 1. Model showing the process and components in the vocational rehabilitation program.

was to examine the benefits from a vocational rehabilitation program for patients suffering from ABI in terms of quality of life, and overall health. In addition, this study examined the direct societal costs of healthcare interventions related to vocational rehabilitation and indirect societal costs related to production loss.

\section{Methods}

\subsection{Design}

This audit is based on information from medical records and has a before and after design.

\subsection{Subjects}

The study includes 45 individuals with ABI, discharged from a vocational rehabilitation program during 2010 and 2011. They were referred to vocational rehabilitation due to remaining cognitive dysfunction and/or due to non-successful return to work after ABI. All subjects were considered for further interventions at the Department of Rehabilitation Medicine. Approximately one year had elapsed from illness/injury onset to the first contact with the rehabilitation team. At onset, all individuals went through a comprehensive initial brain injury assessment that included a medical examination, a neuropsychological assessment, a sensory-motor assessment, and an activity assessment. After the initial assessment, the patients participated in individually designed reha- 
bilitation programs before vocational training interventions took place in cooperation with the employer and social insurance official (Figure 1). In the vocational rehabilitation program, thirty-one individuals (69\%) had their work training at their former employer and all but three of those were given work adapted to their limitations. Five individuals were trained by another employer; four had been unemployed at onset and therefore had no employer. The individuals were assessed concerning work capacity at the end of their work training and a decision on future level of work capacity was made in co-operation with the regional social insurance official and the employer.

\subsection{Intervention}

The vocational rehabilitation program contained several stages (Figure 1). The first stage included interventions related to the initial assessment, individual rehabilitation plans, and supporting and informing patients and relatives. The second stage included all interventions aimed at preparing the patient for a return to work. At the third and last stage, the actual vocational training at the workplace took place.

\subsection{Procedures and Analyses}

Each type of intervention was time estimated via consensus team-discussions by the rehabilitation team. Time was then translated into money using mean salary for professionals (2012 year's salary including payroll tax) plus clinical overhead costs (20\%), resulting in a "price-list" on every documented type of measure. All individuals discharged from the vocational rehabilitation team during 2010 and 2011 were identified. By going through the medical records for each individual and classifying each intervention, the resources used for each individual during the rehabilitation period were identified and each type of intervention was translated into direct costs based on the created "price-list". Thus, each individual had a separate set of interventions and as a consequence also costs.

The societal benefits from calculated production loss for each individual were based on estimated loss of income at first contact and at discharge. Statistics on estimated mean income, including payroll tax for a male/ female with a certain educational level from the year 2009-2011 [26], were used (Table 1).

\subsection{Outcome Variables}

\subsubsection{Costs}

To identify the most expensive stages of the vocational rehabilitation program, estimated costs were grouped into categories of interventions based on the "price-list" and the flowchart describing the different stages of the program process. The alternative course of action was considered to be no rehabilitation intervention. When comparing costs for those alternatives, we assume that production loss would remain as they were at initial contact i.e., as if no vocational rehabilitation interventions were performed. Vocational rehabilitation costs were identified using the calculated time for each professional in each type of intervention (Figure 1).

\subsubsection{Societal Benefits}

Benefits to society were calculated in terms of reduced production loss. To calculate production loss, we compared the working rate for each individual at initial contact and at discharge.

\subsubsection{Quality of Life (QoL) and Estimated Health}

Health-related QoL was documented using the EQ5D [27] at initial contact and at discharge. The EQ5D includes five questions with three alternative answers. The answers are weighted and together they form a weighted index between -0.594 to +1 . Overall health was documented at initial contact and at discharge using EQVAS [27]. EQVAS includes a scale from 0 (worst imaginable health) to 100 (best imaginable health) where the individual makes a mark on a line to illustrate the estimated overall health at that moment.

\subsection{Statistical Analysis}

Statistical analyses were performed using both parametric and non-parametric methods. Paired tests as well as comparisons between groups were made together with correlation analyses. Acceptable level of significance was set at $\mathrm{p} \leq 0.05$. 
Table 1. Mean salary/month for men and women with a certain level of education based on figures from the Swedish Central Bureau of Statistics from the year 2009-2011.

\begin{tabular}{ccc}
\hline Education & Men & \multicolumn{2}{c}{ Women } \\
& - mean salary per $\begin{array}{c}\text { Month including payroll tax } \\
(€)\end{array}$ & $\begin{array}{c}\text {-mean salary per month, including payroll tax } \\
\text { Nine year compulsory school }\end{array}$ \\
Secondary school & 4854.84 & 4264.12 \\
University & 5237.52 & 4502.76 \\
\hline
\end{tabular}

\subsection{Ethical Considerations}

The study did not need approval from the local ethical committee (prop. 2002/03:50 p. 91) since no extra interventions were made and results were based on existing information from medical records and professional assessment protocols. Moreover, individual patients were not identified.

\section{Results}

\subsection{Subjects}

The studied group included the following diagnosis; stroke $(n=17)$, TBI $(n=9)$, brain tumor $(n=8)$, encephalitis or subarachnoidal hemorrhage $(n=4+4)$, anoxia $(n=2)$ and other $(n=1)$. There were 28 men $(62 \%)$ and 17 women (38\%) and the age was on average $45 \pm 12$ years. Average years of education were $13.5 \pm 2$ years. Consequently, 47\% ( $n=21)$ of the subjects had University grade, and 47\% $(n=21)$ had high school level, and three subjects had elementary school level. The group came to vocational rehabilitation on average 15.6 months post illness/injury onset with a range from 2.7 - 87 months. All individuals were fully or partially on sick leave during the whole vocational rehabilitation program. Before illness/injury, 42 individuals (93\%) worked full time, two individuals worked $75 \%$, and one worked $50 \%$. No correlation was found between time from injury to first visit and time from first visit to discharge $(\mathrm{p}=0.08)$.

Results from existing neuropsychological tests were identified for forty individuals. Most of the tests were well-known neuropsychological tests used in clinical practice with patients suffering from ABI [28], including tests measuring cognitive speed (WAIS III Digit symbol, APT RT Inhibition, APT K-test) [29]-[31] and executive functions (Color Word Test, Wisconsin Card Sorting Test, Word fluency, WAIS III Digit span) [31] [32]. The participants generally performed within the lower part of normal range (Wisconsin Card Sorting Test, APT K-test, APT RT Inhibition, Word fluency, WAIS III Digit span) or below the normal range (Digit symbol, Color Word Test). There was a wide range of results within the forty subjects, in all tests. Most individuals described a certain cognitive slowness and that residual cognitive problems affected their daily life. All subjects complained about mental fatigue, impaired stress tolerance, and stimuli sensitivity, factors that reduced their capability to use their cognitive resources entirely. At initial contact, the HAD [33] mean value score ( $\mathrm{n}=39$ ) was $7.47 \pm 4.5$ for anxiety and $5.45 \pm 4$ for depression; 21 individuals (54\%) had an anxiety rate of $\geq 7$ and 13 (33\%) had a depression rate of $\geq 7$. The difference was significant $(\mathrm{p}<0.01)$.

The median time from initial assessment to discharge was 18 months with a wide range $(n=45)$. Consequently, median time from injury to follow-up for the studied group was over 30 months. Work capacity, expressed as full time $(100 \%=40 \mathrm{~h} /$ week), three-quarters $(75 \%)$, half $(50 \%)$, or one quarter $(25 \%)$, can be seen in Table 2. At initial contact with the team, 64\% of the individuals did not work at all. At discharge, 42 (93\%) found some degree of work. By follow-up, all but two (89\%) found work to some extent, most commonly halftime or full-time work (Table 3). Three persons were assessed not having any work capacity at discharge due to physical pain or impaired insight due to cognitive dysfunction, another two patients were considered to have some work capacity and consequently employable, but they had no employment at follow-up. Both were also unemployed at initial contact.

\subsection{Vocational Rehabilitation Costs}

Costs per intervention, the "price-list” (Table 4), was based on estimated time used for each profession and each intervention plus estimated overhead costs (20\%). The time used was discussed and defined through several 
Table 2. Mean production loss at first contact and at discharge. The mean decrease in production loss per individual and month is $€ 1963$.

\begin{tabular}{cccc}
\hline & $\begin{array}{c}\text { Mean production loss at first } \\
\text { contact }(€)\end{array}$ & $\begin{array}{c}\text { Mean production loss at } \\
\text { follow-up (€) }\end{array}$ & $\begin{array}{c}\text { Difference in production } \\
\text { loss (€) }\end{array}$ \\
\hline Per month/Individual & 4409 & 2446 & 1963 \\
Per month/Whole group & 198,410 & 110,091 & 88,319 \\
\hline
\end{tabular}

Table 3. Work capacity for 45 individuals before injury/disease, at initial contact, at discharge and follow-up.

\begin{tabular}{ccccc}
\hline Work capacity \% & Before injury/disease (n) & At initial contact with the team (n) & At discharge (n) & At follow-up \\
\hline 0 & 0 & 29 & 3 \\
25 & 0 & 4 & 7 \\
50 & 1 & 4 & 18 \\
75 & 2 & 4 & 5 \\
100 & 42 & 4 & 4 \\
Total & 45 & 45 & 45 \\
\hline
\end{tabular}

Table 4. The price-list. The cost is based on each professional's estimated time used, which is then translated into monetary terms using the mean salary plus payroll tax and an overhead cost (20\%).

\begin{tabular}{|c|c|}
\hline Intervention & $€$ \\
\hline Prescription & 18.5 \\
\hline Letter & 30.6 \\
\hline Email & 30.6 \\
\hline Phone call (other professions than physician) & 31.3 \\
\hline Medical certificate & 38.2 \\
\hline Letter/referral & 41.6 \\
\hline Psychosocial intervention (social worker and OT) & 52.9 \\
\hline Phone call (physician) & 55.3 \\
\hline Working memory training at home & 58.8 \\
\hline Team conference & 60.8 \\
\hline Individual support (psychologist) & 97.9 \\
\hline Visit to a work place or authority & 114.5 \\
\hline Day-care visit & 116.5 \\
\hline Support to relative & 116.5 \\
\hline Disability certificate & 125.3 \\
\hline Day-care visit—-team ${ }^{*}$ & 145.2 \\
\hline Support to relative--team ${ }^{*}$ & 145.2 \\
\hline Medical health insurance-social insurance office & 167.4 \\
\hline Revisit physician & 211.7 \\
\hline Car driving assessment & 260.4 \\
\hline Visit to a work place or authority—-team ${ }^{*}$ & 261.4 \\
\hline First time visit (physician) & 269.5 \\
\hline Cognitive group therapy (11 sessions) & 420.1 \\
\hline Brain injury assessment—limited (one professions) & 914.4 \\
\hline Working memory group training at the clinic ( 25 sessions) & 970.0 \\
\hline Neuropsychological group training (20 sessions) & 1020.0 \\
\hline Brain injury assessment-team ${ }^{*}$ & 1037.9 \\
\hline
\end{tabular}


meetings with the team members.

Time (costs) related to administration, such as telephone calls and team conferences, were distributed into the three stages as presented in Figure 1, (Table 5). Mean costs per individual for interventions made by the team during vocational rehabilitation were estimated to be $€ 6303 \pm 3197$. The sum of all costs for all 45 individuals during the whole period was estimated to be $€ 283,626$. Looking at the whole process for all individuals, the four most expensive interventions were time for telephone calls (€50182.08), time and travel costs for workplace visits (€45094.32), time for team brain injury assessment (€38401.56), and time for team conferences (€24275.16).

\subsection{Societal Benefits}

Mean production loss was calculated using the percentage of estimated salary loss per month, due to sick leave. The mean decrease in production loss per individual and month from first contact to follow-up was $€ 1963$.

\subsection{Quality of Life and Estimated Health}

Twenty-nine individuals (64\%) filled in the EQ5D at the initial assessment and at discharge. The analysis from the EQ5D index showed a statistical positive difference between measures in the studied group, $\mathrm{m}=0.70 \pm 0.3$ at initial contact compared to $\mathrm{m}=0.80 \pm 0.2$ at discharge $(\mathrm{p}<0.01$ ). The overall estimated health (EQVAS) showed no difference between measures, $\mathrm{m}=68.1 \pm 18.1$ at initial assessment, and $\mathrm{m}=71.4 \pm 19.6$ at discharge $(\mathrm{p}=0.15)$. The EQ5D index at first contact significantly correlated with the HAD depression index scores $\left(\mathrm{r}_{\mathrm{s}}=\right.$ $-0.69, \mathrm{p}<0.05)$ and HAD anxiety scale at first contact $\left(\mathrm{r}_{\mathrm{s}}=-0.67, \mathrm{p}<0.05\right)$.

Table 5. Total costs for the 45 individuals during medical assessment, pre-work training, and work training. Some of the specified interventions from Table 4 are summed up into categories of interventions.

\begin{tabular}{|c|c|c|}
\hline Medical assessment Stage 1 & $€$ & Total €66648.45 \\
\hline First time visit physician & 13505.40 & \\
\hline Medical certificate- early phase ( $20 \%$ of total) & 1923.26 & \\
\hline Brain injury assessment (team and limited) & 44802.36 & \\
\hline Car driving assessment & 1562.40 & \\
\hline Team conference ( $20 \%$ of total) & 4855.03 & \\
\hline Pre-work training Stage 2 & & Total €93278.74 \\
\hline Physician administration (email, phone calls, letters, prescription, referrals, $45 \%$ of total) & 7493.31 & \\
\hline Medical certificate (40 \% of total) & 3846.53 & \\
\hline Revisits to physician ( $50 \%$ of total) & 5821.20 & \\
\hline Group programmes (working memory, neuropsychological training, cognitive training) & 23981.88 & \\
\hline Psychosocial or/and individual support & 4676.04 & \\
\hline Support to relatives & 4561.32 & \\
\hline Administration other professionals (mostly phone-calls) & 14534.52 & \\
\hline Day-care & 18653.88 & \\
\hline Team Conference ( $40 \%$ of total) & 9710.06 & \\
\hline Work training Stage 3 & & Total €123698.41 \\
\hline Physician administration (email, phone calls, letters, prescriptions, referrals, $55 \%$ of total) & 8824.41 & \\
\hline Medical certificate ( $40 \%$ of total) & 3846.53 & \\
\hline Disability certificate & 9207.00 & \\
\hline Revisits to a physician ( $50 \%$ of total) & 5821.20 & \\
\hline Visit to a workplace (one profession or team) & 45094.32 & \\
\hline Administration other professionals (mostly phone-calls) & 40819.05 & \\
\hline Medical health insurance & 375.84 & \\
\hline Team Conference ( $40 \%$ of total) & 9710.06 & \\
\hline Vocational rehabilitation & & Total €283625.60 \\
\hline
\end{tabular}




\subsection{Prediction for Outcome in Production Loss}

No correlation was found between any NP-test and work resumption at discharge. Similarly, there was no correlation between estimated depression and anxiety (HAD) rates and work resumption. Only two variables correlated significantly to outcome in terms of percent in production at discharge. A statistical analysis showed a positive correlation between EQ5D at discharge and percent production $\left(r_{s}=0.44, p<0.05\right)$ and between estimated overall health at discharge EQVAS and percent production $\left(\mathrm{r}_{\mathrm{s}}=0.39, \mathrm{p}<0.05\right)$.

\section{Discussion}

This study's primary objective was to examine the benefits from a vocational rehabilitation program for patients suffering from ABI in terms of quality of life, and overall health. In addition, the study examined the direct societal costs of healthcare interventions related to vocational rehabilitation and indirect societal costs related to production loss.

Our results support clinical experiences and results from other studies [12] [13] showing that patients with ABI who are expected to return to work benefit greatly from vocational rehabilitation support. A long tradition in working with vocational rehabilitation activities together with an ambition to design clinical work based on evidence [10] [24] has resulted in a thoroughly developed program that focuses on individual needs and expectations. This program is probably successful, in part, because it includes other authorities such as the social insurance office, employment service, and, most importantly, the employer, when designing individual support systems for these patients. As labor market policies as well as social insurance systems might differ between countries, each country has to develop its own approach to support patients in returning to work after ABI. However, it has been shown that it can be worthwhile to use specially designed programs and specialized rehabilitation personnel in vocational rehabilitation for patients with cognitive dysfunctions after ABI. A recently published study by Radford et al. [34] compared the benefits and costs of typical care with care provided by specialist vocational rehabilitation interventions. The authors found that $15 \%$ more traumatic brain-injured participants had returned to work after 12 months compared to those who got traditional care. The authors also calculated the costs and found that the specialized vocational rehabilitation was only $£ 75$ (€80.87) greater at one year compared to costs for traditional care. This result supports the findings from our study.

By using already existing data from patient records together with existing internal statistics, it has been possible to use and analyze results and to translate interventions into monetary terms in a sufficiently reliable way. Of those 42 (93\%) patients who had returned to work to some degree at discharge, 40 patients still worked at follow-up. When entering the rehabilitation program, most patients had an employer, a factor that can predict a patient's return to work [13] [35]. From an earlier systematic clinical follow-up (unpublished), we found that 84\% of patients who had managed to return to work at discharge were still working three years later. Our results and clinical experience suggest that most patients with ABI need to have their work and/or work environment adapted. They also need professional support in the planning process together with employers and persons from the social security system.

Because we assumed that patients would remain at the same level of sick leave as when they arrived at the clinic if they had not participated in any vocational rehabilitation interventions, we hypothesized that our results are, at least in part, due to the support the patients received from the multi-disciplinary rehabilitation team [15]. As our analysis indicates, the expenses for the professional team will soon be recovered. And the results support the argument that this type of specialized vocational rehabilitation is cost-effective. This group, although not representative for all working age individuals suffering from ABI, has been found to have a potential to return to work. Since most individuals had mild or moderate cognitive dysfunctions and a relatively high educational level, a generalization of results must be done with caution. However, results from this study agree with results presented by other authors. For example, Sarajuuri et al. [13] showed that $89 \%$ of individuals included in a comprehensive neurorehabilitation program for patients with TBI, were productive at a two-year follow-up, compared to $55 \%$ of controls receiving conventional rehabilitation in the general healthcare system [13]. In vocational rehabilitation research, however, studies often produce conflicting results, inconsistencies that may be due to differences in patient groups, societal resources, and healthcare resources. Hofgren et al. [36] showed that only $18 \%$ of $\mathrm{ABI}$ patients had returned to work one year after attending a rehabilitation center. In a review including 49 studies presented by Van Velzen et al. [15], the authors found that within two years post-injury about $40 \%$ of subjects with non-traumatic and traumatic ABI returned to work. Results also illustrates that those who 
manage to return to work often require changing job demands. The diversity in results could be due to such factors as diversity in the identified groups, differences in countries' social security systems, and access to specialized work-rehabilitation. We included individuals with traumatic as well as non-traumatic ABI knowing that there might be some differences between those groups. However, Van Velzen et al. [15] showed that there was no difference between those groups with respect to finding and maintaining a job two years after injury.

It was difficult to identify predicting factors related to the final level of work production from neuropsychological tests used at the initial assessment. This finding might not be that surprising since patients discharged from vocational rehabilitation, still have cognitive impairments even if they have learned to compensate for, or have had their work adapted for their cognitive dysfunctions. Pre-work as well as work training interventions focus on learning and implementing compensatory strategies.

Health-related QoL and estimated health as measured by EQ5D [27], were the only variables that correlated to the level of production at discharge. Since the HAD depression and anxiety scales were found to have a significant correlation with the Health-related QoL and estimated health at initial assessment, it is reasonable to argue that patients' psychological well-being has a great impact on a patient's ability to return to work. For example, Radford et al. [34] found that those participants who managed to return to work were significantly less anxious and depressed and had significantly better health-related QoL than those who did not manage to return to work.

The studied group was provided a mixture of interventions that were specifically designed to address individual needs (Figure 1), a strategy that proved to be effective as well as efficient. The total cost for the whole group was estimated to be $€ 283625.60$. The resources spent on the initial medical rehabilitation stage were about $24 \%$ of the total costs. Those costs included a comprehensive individual brain injury assessment with a medical examination, neuropsychological assessment, sensory-motor assessment, and activity assessment. The activity assessment evaluated how the brain injury influenced daily life, work, education, work anamnesis, and the patient's attitudes concerning return to work. This important initial stage requires teamwork to assess different aspects of the patient's resources and dysfunctions, an assessment that then can be used to develop a plan for the whole rehabilitation process. The second stage in the vocational rehabilitation process includes actions aimed to improve certain functions and strengthen emotional, social, and behavioral capacity (Figure 1 and Table 5). At this stage, the program focused on increasing self-awareness, understanding the consequences of the injury (e.g., significant fatigue and decreased working memory), and developing coping strategies to handle secondary consequences (e.g., slowness and decreased attention) [10] [24]. This stage of the process accounts for around 33\% of the total costs. Although this part of the process for a majority of the patients is the most time consuming and requires the most interventions that take place at the hospital, several of these interventions are group programs, an approach that is relatively cost-effective. The last part of the rehabilitation process, interventions related to the work place and vocational training, accounted for the largest proportion of the costs (44\%). Visits to the work place and above all, telephone consultations (employers, patients, persons at the social insurance office, relatives) accounted for $69 \%$ of those work-training costs.

Because it is difficult to manage daily demands and especially work requirements for patients suffering from cognitive dysfunctions after an $\mathrm{ABI}$, it is important for the health-care to be able to offer $\mathrm{ABI}$ patients vocational rehabilitation including a specialized multi-professional team. The studied group consisted of a relatively small number of individuals who received a well-structured and individually suited vocational rehabilitation program, over a long period of time. One question to study in the future is whether it is possible to reduce some of the interventions and thus be able to support a larger number of individuals while still receiving the same positive results. The individuals reported stress and fatigue as a consequence of brain injury. It may have been interesting to use instruments to measure their stress and fatigue level because these factors probably affect their ability to return to work.

\section{Conclusion}

The specialized multidisciplinary vocational rehabilitation program that has been evaluated has been found to lead to positive results both from a patient as well as a societal perspective. Healthcare costs for provided interventions are considered most reasonable in relation to calculated societal savings. Patient-estimated QoL improved during the vocational rehabilitation process indicating that being able to return to work has an impact on a patient's wellbeing. Estimated QoL as well as estimated health at discharge correlated to percent work produc- 
tion at discharge. Although clinical experience is considered the lowest level of evidence, we believe the results are significant because of the nearly 30 years of experience with vocational rehabilitation interventions and follow-ups with both patients and their relatives. To further our understanding of these issues, we plan to conduct another study using a control group from another hospital that has no vocational rehabilitation resources within the healthcare system.

\section{Study Limitations}

The main limitation of this study is the lack of controls. However, as Turner-Stokes et al. [19] point out, "Problems following ABI vary. Consequently, different interventions and combinations of interventions are required to suit the needs of patients with different problems. Not all questions in rehabilitation can be addressed by randomized controlled trials or other experimental approaches. Some questions include which treatments work best for which patients over the long term, and which models of service represent value for money in the context of life-long care. Rehabilitation for brain injury is such an individualized and long-term process that it can be difficult to draw general conclusions from research studies. In future, such questions will need to be set alongside practice-based evidence gathered from large systematic, longitudinal cohort studies conducted in the context of routine clinical practice" [19].

When comparing the production loss from initial contact to follow-up, we calculated costs based on the hypothesis that the patient group would remain at the same level of sick leave if they received no vocational rehabilitation support. This is an assumption based on uncertainty. On the other hand, we know from clinical experience that patients, who have resumed working without support, often fail. They are unable to manage previous work leading to new periods of sick leave or at worst, dismissal. Another limitation is the reliance on information from medical and patient records. Data were collected from medical records on individuals leaving the department during 2011-2012. Since the hospital introduced digital medical records in 2009 and consequently every intervention has to be documented, we find that the data are sufficiently reliable and objective.

\section{Conflict of Interest}

The authors declare no conflict of interest. Research grants, has been received for this study from the County Council of Östergötland, Sweden.

\section{References}

[1] Ontario Brain Injury Association (2011) What Is Acquired Brain Injury. www.Obia.ca

[2] (1996) World Health Organization, Geneva.

[3] Cicerone, K., Dahlberg, C., Kalmar, K., Langenbahn, D.M., Malec, J.F., Bergquist, T.F., Felicetti, T., Giacino, J.T., Harley, J.P., Harrington, D.E., Herzog, J., Kneipp, S., Laatsch, L. and Morse, P.A. (2000) Evidence-Based Cognitive Rehabilitation: Recommendations for Clinical Practice. Archives of Physical Medicine and Rehabilitation, 8, 15961615. http://dx.doi.org/10.1053/apmr.2000.19240

[4] Cicerone, K., Dahlberg, C., Malec, J.F., Langenbahn, D.M., Felicetti, T., Kneipp, S., Ellmo, W., Kalmar, K., Giacino, J.T., Harley, J.P., Laatsch, L., Morse, P. and Catahese, J. (2005) Evidence-Based Cognitive Rehabilitation: Updated Review of the Literature from 1998 through 2002. Archives of Physical Medicine and Rehabilitation, 86, 1681-1692. http://dx.doi.org/10.1016/j.apmr.2005.03.024

[5] Thurman, D., Alverson, C., Dunn, K., Guerrero, J. and Sniezek, J. (1999) Traumatic Brain Injury in the United States: A Public Health Perspective. Journal of Head Trauma Rehabilitation, 14, 602-615. http://dx.doi.org/10.1097/00001199-199912000-00009

[6] Fortune, N. and Wen, X. (1999) The Definition, Incidence and Prevalence of Acquired Brain Injury in Australia. Australian Institute of Health and Welfare, Canberra.

[7] Johansson, B., Saarela, T. and Stenson, S. (2013) Acquired Brain Injury [In Swedish]. http://www.1177.se/Vastmanland/Tema/Funktionsnedsattning/Habilitering/Diagnoser/Forvarvade hjarnskador/

[8] Eriksson, G., Eriksson, L., Ottander, A., Bexell-Brantefors, K., Lindgren, F. and Morén, L. (2000) The Situation for Persons with Aquired Brain Injury [In Swedish]. County Council, Uppsala.

[9] Consensus National Institute of Health (1999) Rehabilitation of Persons with Traumatic Brain Injury. Journal of the American Medical Association, 10, 974-983.

[10] Lundqvist, A., Grundström, K., Samuelsson, K. and Rönnberg, J. (2010) Computerized Training of Working Memory 
in a Group of Patients Suffering from Acquired Brain Injury. Brain Injury, 24, 1173-1183. http://dx.doi.org/10.3109/02699052.2010.498007

[11] Durand, M.J. and Loisel, P. (2001) Therapeutic Return to Work: Rehabilitation in Workplace. Work, 17, 57-63.

[12] Wrona, R.M. (2010) Disability and Return to Work Outcomes after Traumatic Brain Injury: Results from the Washington State Industrial Insurance Fund. Disability and Rehabilitation, 32, 650-655. http://dx.doi.org/10.3109/09638280903186327

[13] Sarajuuri, J., Kaipio, M.L., Koskinen, S., Niemelä, M., Servo, A. and Vilkki, J. (2005) Outcome of a Comprehensive Neurorehabilitation Program for Patients with Traumatic Brain Injury. Archives of Physical Medicine and Rehabilitation, 86, 2296-2302. http://dx.doi.org/10.1016/j.apmr.2005.06.018

[14] Nishino, A., Sakurai, Y., Tsuji, E., Arai, H., Uenohara, H., Suzuki, S. and Li, J.H. (1999) Resumption of Work after Aneurysmal Subarachnoid Haemorrhage in Middle-Aged Japanese Patients. Journal of Neurosurgery, 90, 59-64. http://dx.doi.org/10.3171/jns.1999.90.1.0059

[15] van Velzen, J., van Bennekom, C., Edelaar, M., Sluiter, J. and Frings-Dresen, M. (2009) How Many People Return to Work after Acquired Brain Injury? A Systematic Review. Brain Injury, 23, 473-488. http://dx.doi.org/10.1080/02699050902970737

[16] Grosswasser, Z., Melamed, S., Agranov, E. and Keren, O. (1999) Return to Work as an Integrated Outcome Measure Following Traumatic Brain Injury. Neuropsychological Rehabilitation, 9, 493-504. http://dx.doi.org/10.1080/096020199389545

[17] Klonoff, P., Watt, L., Dawson, L., Henderson, S., Gehrels, J.A. and Wethe, J.V. (2006) Psychosocial Outcomes 1-7 Years after Comprehensive Milieu-Oriented Neurorehabilitation: The Role of Pre-Injury Status. Brain Injury, 20, 601612. http://dx.doi.org/10.1080/02699050600744301

[18] Johnstone, B., Vessel, R., Bounds, T., Hoskins, S. and Sherman, A. (2003) Predictors of Success for State Vocational Rehabilitation Clients with Traumatic Brain Injury. Archives of Physical Medicine and Rehabilitation, 84, 161-167. http://dx.doi.org/10.1053/apmr.2003.50098

[19] Turner-Stokes, L., Nair, A., Sedki, I., Disler, P.B. and Wade, D.T. (2005) Multi-Disciplinary Rehabilitation for Acquired Brain Injury in Adults of Working Age. Cochrane Database of Systematic Reviews. http://dx.doi.org/10.1002/14651858.CD004170.pub2

[20] Black, C. (2008) Working for a Healthier Tomorrow. The Stationery Office, London.

[21] SBU-Rapport nr 177/1:159-190.

[22] Drummond, M.F., Sculpher, M.J., Torrance, G.W., O’Brien, B.J. and Stoddart, G.L. (2005) Methods for the Economic Evaluation of Health Care Programmes. 3rd Edition, Oxford University Press, Oxford.

[23] (1999) Socialförsäkringslagen [The Swedish Social Insurance]. 799.

[24] Lundqvist, A., Linnros, H., Orlenius, H. and Samuelsson, K. (2010) Improved Self-Awareness and Coping Strategies for Patients with Acquired Brain Injury-A Group Therapy Programme. Brain Injury, 24, 823-832. http://dx.doi.org/10.3109/02699051003724986

[25] World Health Organization (2001) International Classification of Functioning, Disability and Health: ICF. WHO, Geneva.

[26] Swedish Central Bureau of Statistics. http://www.scb.se/statistik/am0110/am0110 db.asp/

[27] EQ-5D. http://www.euroqol.org

[28] Lezak, M. (2004) Neuropsychological Assessment. Oxford University Press, New York.

[29] Levander, S. (1988) An Automated Psychological Test Battery. IBM-PC Version (APT-PC). Research Reports from the Department of Psychiatry \& Behavioral Medicine, University of Trondheim, Trondheim.

[30] Wechsler, D. (1997) Wechsler Adult Intelligence Scale. 3rd Edition, The Psychological Corporation, San Antonio.

[31] Delis, D., Kaplan, E. and Kramer, H. (2001) D-KEFS. Technical Manual. San Antonio TX. The Psychological Corporation, San Antonio.

[32] Loong, J. (1990) Wisconsin Card Sorting Test. Neuropsychological Assessment Software and User's Manual. Psychological Assessment Resources, Inc., Lutz.

[33] Zigmond, A.S. and Snaith, R.P. (1983) The Hospital Anxiety and Depression Scale. Acta Psychiatrica Scandinavica, 67, 361-370. http://dx.doi.org/10.1111/j.1600-0447.1983.tb09716.x

[34] Radford, K., Phillips, J., Drummond, A., Sach, T., Walker, M., Tyerman, A., Haoubi, N. and Jones, T. (2013) Return to Work after Traumatic Brain Injury: Cohort Comparison and Economic Evaluation. Brain Injury, 27, 507-520. http://dx.doi.org/10.3109/02699052.2013.766929

[35] Gollaher, K., High, W., Sherer, M., Bergloff, P., Boake, S., Young, M.E. and Ivanhoe, C. (1998) Prediction of Employ- 
ment Outcome One to Three Years Following Traumatic Brain Injury (TBI). Brain Injury, 12, 255-263. http://dx.doi.org/10.1080/026990598122557

[36] Hofgren, C., Esbjörnsson, E. and Sunnerhage, K.S. (2010) Return to Work after Acquired Brain Injury: Facilitators and Hindrances Observed in a Sub-Acute Rehabilitation Setting. Work, 30, 431-439. 
Scientific Research Publishing (SCIRP) is one of the largest Open Access journal publishers. It is currently publishing more than 200 open access, online, peer-reviewed journals covering a wide range of academic disciplines. SCIRP serves the worldwide academic communities and contributes to the progress and application of science with its publication.

Other selected journals from SCIRP are listed as below. Submit your manuscript to us via either submit@scirp.org or Online Submission Portal.
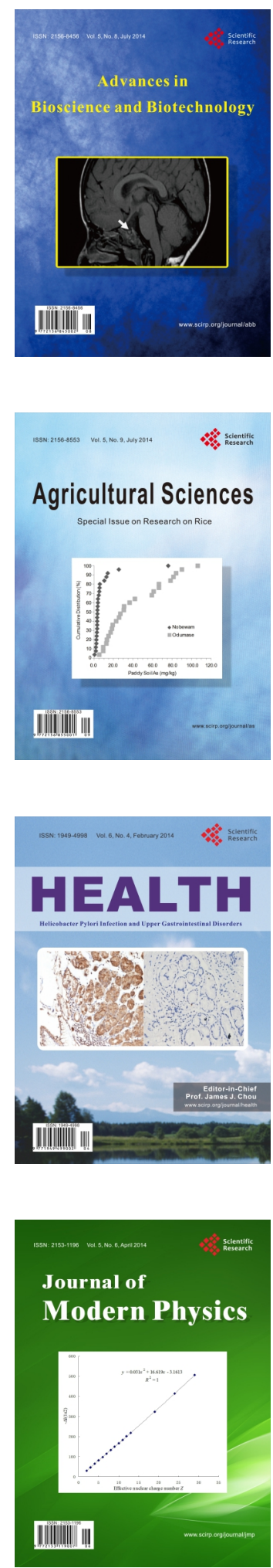
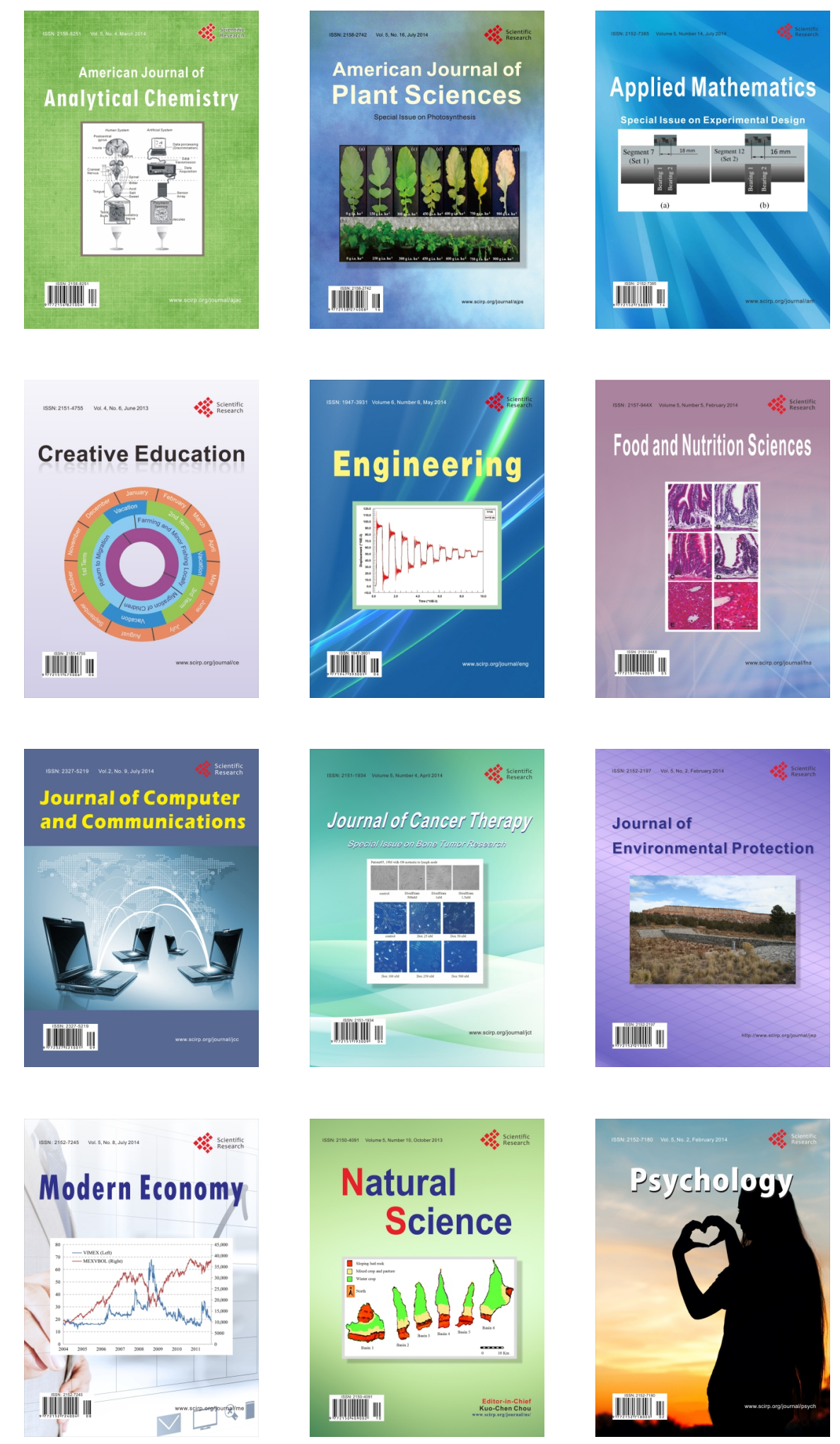